REVISTA DE GEOCIÊNCIAS DO NORDESTE

Northeast Geosciences Journal

v. $7, \mathrm{n}^{\circ} 2(2021)$

ISSN: 2447-3359

https://doi.org/10.21680/2447-3359.2021v7n2ID18311

\title{
O RISCO DE DESASTRE TECNOLÓGICO NA PONTE NEWTON NAVARRO, NATAL - RN, BRASIL
}

\author{
Jhonathan Lima de Souza ${ }^{1}$; Francisca Leiliane \\ Sousa de Oliveira ${ }^{2}$; Lutiane Queiroz de Almeida ${ }^{3}$ \\ Marysol Dantas de Medeiros ${ }^{4}$
}

${ }^{1}$ Doutorando em geografia, Instituto de Geociências, UNICAMP. Campinas/SP.Brasil.

ORCID:https://orcid.org/0000-0003-2351-3266

Email: jhonathanscout@ufrn.edu.br

${ }^{2}$ Doutora em geografia, Laboratório de Geoprocessamento Departamento de Geografia, UECE. Fortaleza/CE. Brasil ORCID: https://orcid.org/0000-0003-4248-4536

Email: leila.geografia@gmail.com

${ }^{3}$ Doutor em geografia, Grupo de Pesquisa Dinâmicas Ambientais, Riscos e Ordenamento do Território, Departamento de Geografia, UFRN, Natal/RN. Brasil.

ORCID: https://orcid.org/ 0000-0002-6604-5987

Email: lutianealmeida@ hotmail.com

${ }^{4}$ Doutora em Geografia, Prodema, UFC, Fortaleza/CE. Brasil ORCID: https://orcid.org/0000-0001-6055-170X

Email: marysol.dantas@hotmail.com

\section{Resumo}

$\mathrm{O}$ presente trabalho discute a temática riscos tecnológicos associados a estruturas de pontes. A área de estudo em questão foi a ponte Newton Navarro e os riscos de colisões de navios nos pilares em função da ausência dos dispositivos de segurança. A metodologia do trabalho deu-se por meio de pesquisa bibliográfica documental em jornais e banco de dados públicos do Ministério Público do Rio Grande do Norte e da Secretaria de Meio Ambiente e Urbanismo de Natal. A análise do material pesquisado resultou no tratamento de imagens de plantas do projeto executivo da ponte, cartografia e as visitas in loco, com o suporte da Marinha do Brasil, para verificar os pilares da ponte. De acordo com os principais resultados foi constatada a ausência dos dispositivos de segurança desde o processo executivo da ponte.

Palavras-chave: Risco tecnológico; Vulnerabilidade estrutural; Ponte estaiada.

\begin{abstract}
THE RISK OF TECHNOLOGICAL DISASTER IN THE NEWTON NAVARRO BRIDGE, NATAL - RIO GRANDE DO NORTE STATE, BRAZIL
\end{abstract}

\begin{abstract}
The present work deals with the technological risks associated with bridge structures. The study area in evidence was the Newton Navarro bridge and the ships collision risks in the bridge pillars due to the absence of safety devices. The work methodology was based on newspapers bibliography research, public database of the Public Ministry of the Rio Grande do Norte State, and the Secretary of Environment and Urbanism of Natal city. The analysis of the researched material resulted in the images processing of the executive design projects of the bridge, cartography, and the on-site visits with the Brazilian Navy, to verify the bridge pillars. According to the main results, the absence of safety devices since the bridge's executive process was found.
\end{abstract}

Keywords: Technological risk; Structural vulnerability; Cablestayed bridge. EL RIESGO DE DESASTRE TECNOLÓGICO EN EL
PUENTE NEWTON NAVARRO, NATAL - RN, BRASIL

\section{Resumen}

Este artículo analiza los riesgos tecnológicos asociados con las estructuras de puentes. El área de estudio en cuestión fue el puente Newton Navarro y los riesgos de colisiones de barcos en los pilares por ausencia de dispositivos de seguridad. La metodología del trabajo se llevó a cabo mediante la búsqueda bibliográfica documental en periódicos y bases de datos públicas del Ministerio Público de Rio Grande do Norte y la Secretaría de Medio Ambiente y Urbanismo de Natal. El análisis del material investigado resultó en el tratamiento de imágenes vegetales del diseño ejecutivo del puente, cartografía y visitas in situ, con el apoyo de la Armada de Brasil, para verificar los pilares del puente. Según los principales resultados, se constató la ausencia de dispositivos de seguridad desde el proceso ejecutivo del puente.

Palabras-clave: Riesgo tecnológico; Vulnerabilidad estructural; Puente atirantado. 


\section{INTRODUÇÃO}

O Brasil possui uma rede hidrográfica com grande extensão, tanto de rios como de águas marítimas. Visto esse fator, o transporte aquaviário é um dos mais importantes modais de cargas do país. O trânsito de importações e exportações portuárias contribuem para o crescimento da economia e assim como o aumento do fluxo de navios nos estuários.

Em face da elevada circulação de embarcações em áreas portuárias no Brasil, há uma preocupação referente a vulnerabilidade de estruturas das pontes pois estas não apresentam dispositivos de segurança. Assim, na tentativa de mitigar os riscos associados a colisões de embarcações em pontes é necessário que as hidrovias possuam estruturas adequadas oferecendo maior segurança no tráfego de embarcações.

Pontes são edificações complexas, as quais exigem um bom projeto executivo. Para isso, é necessário grande aporte financeiro, recursos este advindo do erário público, assim, presume-se que essas estruturas tenham alto nível de durabilidade. Todavia, caso o projeto da ponte não apresente elementos importantes como os dispositivos de segurança, no futuro, essa infraestrutura pode carecer de aditivos no projeto ou de grandes manutenções, onerando ainda mais os cofres do Estado (VITÓRIO, 2008).

De acordo com Consolazio et al., (2008), ocorre pelo menos uma colisão grave por ano de embarcações em pilares de pontes no mundo. Essas colisões são ocasionadas pelas condições de mau tempo acarretando baixa visibilidade, além de fortes correntes de vento e ausência de dispositivos de segurança, tais como instrumentos de navegação nos canais e falhas mecânicas.

Para Ferreira (2000), são comuns os acidentes que envolvem embarcações em hidrovias brasileiras. Os acidentes acontecem por falta de sinalização adequada nos canais de manobra e por falta de defensa em pilares de pontes. O elevado trânsito de embarcações propicia a possibilidade de colisões nessas estruturas, podendo ocasionar eventos desastrosos como impactos ambientais, estruturais e até óbitos de pessoas. Dessa forma, a adoção da implementação de dispositivos de segurança em pontes, são fundamentais para evitar danos maiores.

O rio Potengi é a principal bacia hidrográfica que corta a cidade de Natal, seu estuário encontra-se localizado entre as praias da Redinha e a praia do Forte, a localidade é conhecida como Boca da Barra. Nessa área foi construída a ponte Newton Navarro, sendo a maior ponte do Estado do Rio Grande do Norte, e a porta de entrada para o porto de Natal (Figura 1).

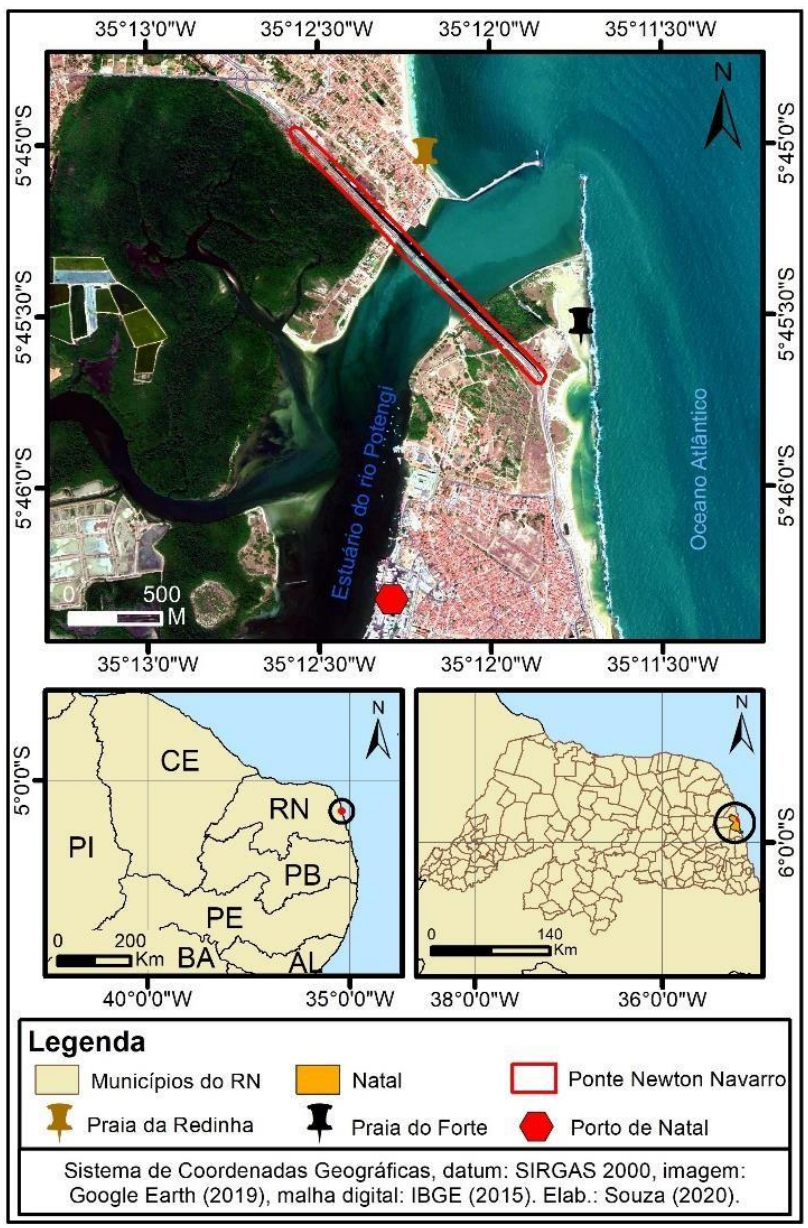

Figura 1 - Mapa de localização da ponte Newton Navarro. Fonte: acervo do autor (2019).

A ponte Newton Navarro foi projetada para atender o fluxo de 60 mil veículos por dia, atualmente, cerca de 39 mil veículos trafegam diariamente em sua estrutura. Essa é uma via imprescindível para a mobilidade do município de Natal e os demais municípios da região metropolitana Norte, em sua estrutura passam 13 linhas de ônibus urbanos do município (SEMURB, 2008; TRIBUNA DO NORTE, 2018).

No Brasil foram registrados diversos casos de colisões de embarcações em pilares de pontes, como exemplo tem-se a colisão recente de uma embarcação nas mesoestruturas da ponte sobre o Rio Moju no Pará em 2019. A ocorrência de eventos desse porte requer atenção para a ponte Newton Navarro, visto que em sua estrutura não há dispositivos de segurança adequados contra colisões para a proteção dos pilares.

Não obstante ser construída em moldes estaiados e com complexo projeto executivo a ponte Newton Navarro não contém defensas para proteção dos pilares contra colisões náuticas. Em projetos da Companhia Docas do Rio Grande do Norte -

CODERN (2019) existe a possibilidade da construção de "dolfins" na ponte em questão, esse mecanismo de segurança é formado por uma estrutura circular com estacas de fundação ancoradas no leito 
do rio, localizando nos arredores dos pilares das pontes. Silva (2016) destaca que os "dolfins" são estruturas de proteção contra colisões de embarcações, sua função é de proteger os pilares para amortecer impactos. A Figura 2 apresenta as plantas do projeto, em destaque é possível constatar a ausências do dispositivo "dolfins".
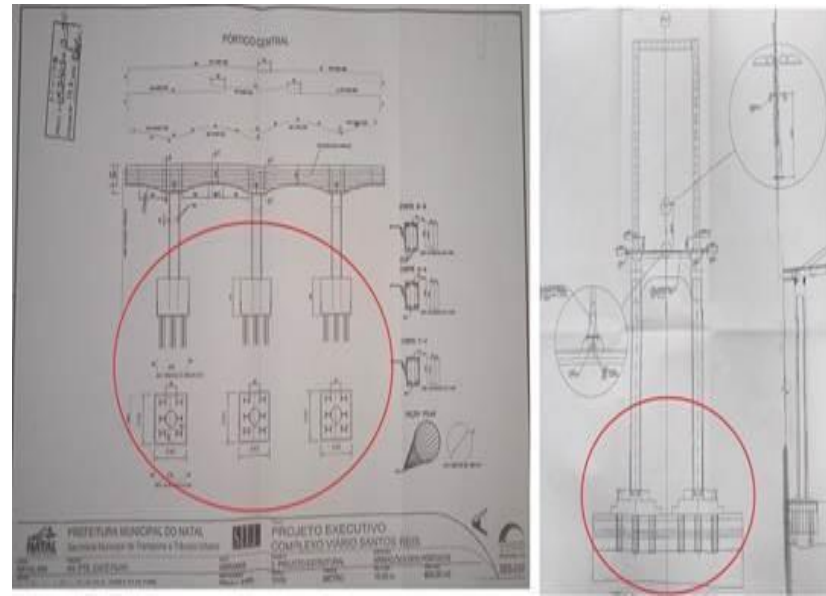

Figura 2 - Projeto executivo da ponte Newton Navarro sem as defensas de segurança. Fonte: Modificado pelos autores a partir de SEMURB (2008).

Em consequência da ausência dos dispositivos de segurança e o risco em função disto para a estrutura da ponte e para os transeuntes, o Ministério Público Estadual (MPE) condenou o Estado do Rio Grande do Norte e a Prefeitura de Natal pela não realização das adequações estruturantes orientadas, todavia, após decisão judicial, a instalação de defensas não foi realizada, condicionando o risco de desastre na ponte através da possibilidade de uma colisão náutica nos pilares da estrutura.

Diante da problemática exposta, tem-se por objetivo discutir neste artigo questões relacionadas ao risco tecnológico em pontes, com enfoque na ponte Newton Navarro em Natal, Rio Grande do Norte. Este trabalho tem o propósito de atuar como ferramenta de divulgação do problema junto à população potiguar, visto que a ponte Newton Navarro é um importante equipamento rodoviário para o Estado.

\section{METODOLOGIA}

A pesquisa foi realizada por meio de procedimentos teóricos e procedimentos empíricos.

Para os procedimentos teóricos inicialmente realizou-se um levantamento bibliográfico sobre riscos tecnológicos com abordagens em estruturas de construção civil. Para nortear questões ligadas ao risco de maneira geral utilizou-se trabalhos de Veyret (2007), Almeida (2010) e Souza et al. (2018). Para a análise do risco de cunho tecnológico utilizou-se o trabalho de Lieber e Romano-Lieber (2005).

Os procedimentos empíricos foram compostos por delimitação da problemática e do recorte da área de estudo. Para isso, foram consultados arquivos da Secretaria de Meio Ambiente e Urbanismo de Natal, afim de obter acesso às plantas do projeto de Estudo de Impacto Ambiental/Relatório de Impacto Ambiental (EIA/RIMA) e o projeto executivo da obra da ponte Newton Navarro. Além disso, foram consultados os processos de ação civil pública no Ministério Público Estadual, bem como o processo de condenação da Prefeitura de Natal e do Governo do Estado do Rio Grande do Norte e artigos jornalísticos que serviram para nortear a problemática. A seguir, foram confeccionadas a cartografia e o tratamento das imagens do projeto da obra e por fim, a realização de visitas in loco, com o apoio da Marinha do Brasil, para fazer a vistoria na estrutura (Figura 3).

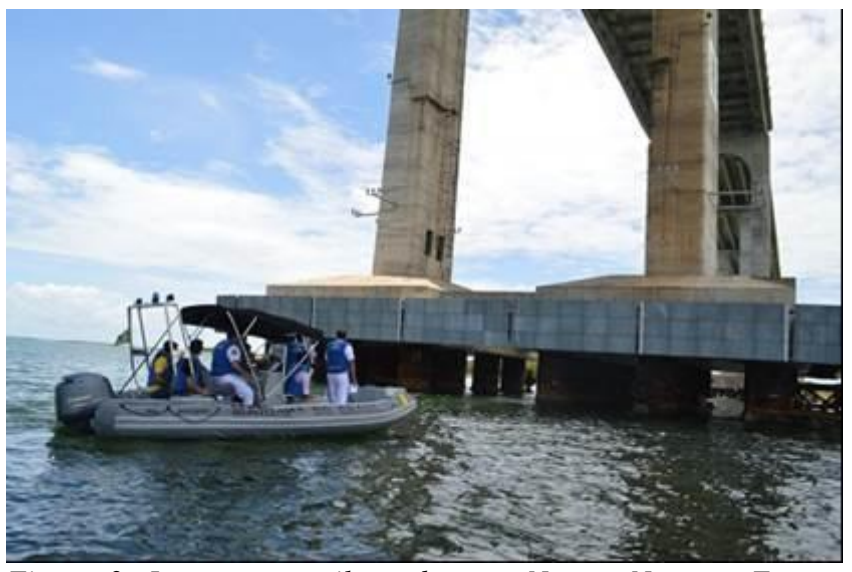

Figura 3 - Inspeção nos pilares da ponte Newton Navarro. Fonte: acervo dos autores (2017).

\section{RESULTADOS E DISCUSSÃO}

\subsection{A segunda ponte sobre o Rio Potengi}

Em 1986 foram realizados estudos pela Empresa Brasileira de Transportes Urbanos (EBTU), com a finalidade de verificar a possibilidade da travessia de balsas de automóveis entre as margens do rio Potengi, no intuito de desafogar o fluxo da ponte de Igapó. Porém, somente em 1995 a gestão municipal autorizou o transporte de veículos aquáticos, entre Santo Reis e Redinha (SEMURB, 2008).

Para atravessar o rio Potengi indo do bairro Santo Reis à Redinha, o transporte utilizado eram as antigas balsas ou barco de pescadores, que realizavam esse serviço de forma irregular. Em 1994, o Estado disponibilizou linhas para a travessia por meio de barcos próprios para transportes de passageiros (SEMURB, 2008).

Com o aumento da frota automobilística de Natal, o Estado viu a necessidade da construção de uma segunda ponte no estuário do rio Potengi, no sentido de desafogar o fluxo da ponte de Igapó. A partir disso, foram idealizados os primeiros estudos de viabilidade da construção da segunda ponte (SEMURB, 2008).

A primeira licitação foi no ano de 1996, porém, não foi implementada, visto que a única empresa que concorreu não pode executar a obra devido a irregularidades no projeto. Ao final do mesmo ano, foi realizada a segunda licitação, porém, embora o contrato tenha sido firmado com a empresa vencedora, a obra não foi iniciada (SEMURB, 2008). 
O terceiro processo licitatório foi em 1998, tendo a possibilidade de ser uma parceria pública privada, de modo que a construção e operação da ponte seriam da empresa ganhadora do processo. Com as taxas do pedágio da operação a construtora teria o retorno do valor investido na construção da ponte. Na ocasião a empresa CEJEN Engenharia foi à única que participou do processo, sendo responsável pela construção e operação da segunda ponte no estuário do rio Potengi (SEMURB, 2008).

A construção da segunda ponte no estuário do rio Potengi teve como objetivo atender a necessidade do fluxo de descolamento e transporte da população natalense, entre as áreas centrais da cidade e o bairro da Redinha. Neste sentido, com a construção da ponte os acessos às zonas Leste e Norte ficaram mais fáceis, bem como aos munícipios adjacentes à Zona Norte de Natal. Além disso, a ponte também teve como finalidade dispor de equipamento para o fomento do turismo no litoral Potiguar, bem como servir de um novo corredor de entrada e saída da cidade (SEMURB, 2008).

O projeto inicial da construção da segunda ponte no estuário do rio Potengi, a futura ponte Newton Navarro, data do ano de 1992, porém, por falta de definições no projeto a obra não foi iniciada. Em 2003, o governo assumiu a responsabilidade pela obra, assim, o projeto é retomado e em 2004 são iniciadas as obras. As empresas Protende, Enescil, Construbase e Construtora Queiroz Galvão participaram da construção da ponte, cujo orçamento inicial era de 170 milhões de reais e passou a 195 milhões de reais no final da obra (MAZARIM, 2011).

Para os idealizadores do projeto da construção da segunda ponte sobre o rio Potengi, a estrutura teve como objetivos secundários viabilizar as economias local, regional e nacional, com a complementação da ampliação das atividades portuárias, revitalização do bairro Ribeira, incremento da rede hoteleira por meio da movimentação de turistas, da valorização imobiliária das praias da Redinha, Genipabu e adjacências, como o fomento da vida noturna na região periférica próxima a ponte (SEMURB, 2008).

A ponte Newton Navarro (Figura 4), também conhecida como ponte Forte-Redinha ou ponte de Todos, localiza-se entre os bairros da Redinha e Santos Reis. Foi inaugurada no ano de 2007 e atualmente atente o fluxo de 60 mil veículos por dia. Projetada pelo engenheiro Mario de Miranda, a estrutura possui extensão total de $1.780 \mathrm{~m}$ e $400 \mathrm{~m}$ no vão central. A ponte de modelo estaiada, é fixada por quatro pilares de $140 \mathrm{~m}$ de altura a partir da superfície d'água e $56 \mathrm{~m}$ de altura da laje do vão central até a superfície d'água. Por suas características monumentais, a ponte atrai a atenção de natalenses e turistas diariamente (MAZARIM, 2011).

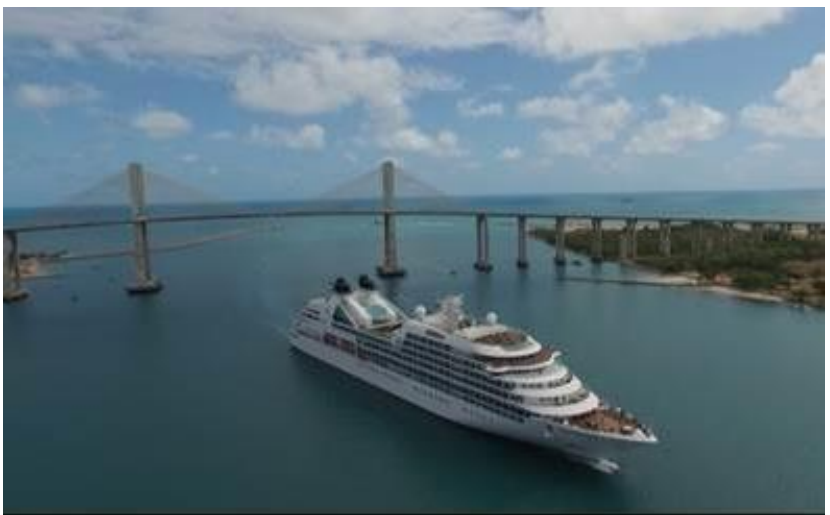

Figura 4 - Ponte Newton Navarro - Natal/RN. Fonte: CODERN (2019).

\subsection{Risco tecnológico associado a estruturas rodoviárias}

Deve ser considerado que em toda atividade que tenha envolvimento humano existe associação ao risco. Em estruturas de pontes os riscos estão envolvidos desde a fase do projeto, passando pela construção e operação. Para Almeida (2010), o advento das técnicas propiciou a construção de uma série de edificações. Assim, com a grande quantidade desses equipamentos os riscos aumentaram em decorrência da utilização por grandes fluxos de pessoas.

Do ponto de vista conceitual para Castro et al., (2005), o risco está enquadrado em quatro categorias: riscos ambientais, riscos tecnológicos, riscos socais e riscos biológicos. Diante disso, o emprego da temática risco deverá ser utilizada conforme a área que cada estudo se propõe.

De acordo com Field et al., (2012) em Painel

Intergovernamental sobre Mudanças Climáticas - IPCC, o conceito do risco remete a um determinado período de tempo, onde ocorre uma alteração brusca no funcionamento normal de

uma comunidade em função de eventos físicos, os quais interagem com meios vulneráveis, propiciando assim efeitos adversos sobre os humanos, materiais, econômicos e ambientais.

Ainda dentro desse debate Veyret et al., (2007) aborda que o risco é uma função dada por $\mathrm{R}(\mathrm{f})=\mathrm{P} \times \mathrm{V}$, onde $\mathrm{P}$ trata-se do perigo, do evento em potencial e $\mathrm{V}$ é a vulnerabilidade do individuo ou de um grupo. Nesse sentido, pode-se destacar o conceito de desastre, este sendo o próprio evento em si, o acontecimento.

Sobre o conceito do desastre Field et al., (2012) define como alteração no funcionamento de uma dada comunidade, em virtude da vulnerabilidade. Assim ocasionando danos humanos, ambientais, econômicos e matérias, os quais carecem de respostas emergenciais, no sentido de satisfazer as necessidades humanas que requerem respostas imediatas de recuperação.

De acordo com Quarantelli (1998) o desastre é um evento que acontece em um dado espaço em uma determinada fração do tempo, o qual ocorre após os gatilhos de perigos serem deflagrados, assim causando destruição e prejuízos materiais, humanos e ambientais, sendo ratificado ou agravado pela falta da capacidade de lidar da comunidade com esse evento.

Cabe destacar que de acordo com Escritório das Nações Unidas para a Redução de Riscos de Desastres - UNISDR (2016), 
há diferença entre o risco de desastre e o desastre em si, o primeiro remete as possíveis perdas, tudo que foi provocado pelo desastre, tais como: vidas humanas, danos matérias, ambientais e econômicos que poderia acontecer em um dado lugar e em um dado tempo. Já o desastre refere-se a um evento danoso o qual excede a capacidade das pessoas de lidarem com esse evento, ocasionando danos humanos, ambientais, materiais e econômicos, para Lavel (2003) este conceito é definido como uma situação crítica diretamente ligada a perdas humanas e materiais de forma considerável.

Neste trabalho o cerne da discussão será pautado no risco em sua categoria tecnológica. O risco tecnológico é caracterizado pela falta da capacidade ou negligência do emprego da técnica utilizadas nas construções de edificações. Se o eventual dano potencial tiver como origem risco de cunho tecnológico, esse desastre também será caracterizado como um desastre tecnológico (LIEBER; ROMANO-LIEBER, 2005).

Em todo o mundo há relatos de desastres tecnológicos relacionados a pontes e viadutos. Por exemplo: o desabamento da ponte do rio Mississipi no estado do Mississipi nos Estados Unidos da América, que resultou em dez óbitos e sessenta feridos; em 2016 como consequência da colisão de um navio de cruzeiro com uma ponte no canal Meno-Danúbio, na Baviera, Alemanha, duas pessoas morreram; a ponte italiana na autoestrada A14, na cidade de Camerano, na província de Ancona, que desabou em março de 2017; e a ponte que desabou e vinte e duas pessoas morreram em 2018, também na Itália, na estrada A10 em Gênova; ainda em 2018, um navio bateu em uma ponte na passagem do Tufão Jebi no Japão (VITORIO, 2008; G1, 2016; SOUZA et al., 2018; EM, 2018; G1, 2019).

O Brasil possui histórico de casos de desastres tecnológicos associados a estruturas rodoviárias, tais como: a ponte dos Remédios sobre o rio Tietê, no estado de São Paulo, que colapsou em 1997; a ponte sobre a represa de Capivari na rodovia Regis Bittencourt, no Paraná, ruiu e duas pessoas morreram em 2005; o viaduto da Pompeia em São Paulo teve sua estrutura comprometida após um incêndio em 2012. No ano de 2014 uma embarcação colidiu contra a ponte do Rio Três Forquilhas, na BR101 no RS e quatro pessoas caíram na água; ainda em 2014 um viaduto em Belo Horizonte desabou. Em 2015 a ponte do rio Tamanduateí em São Paulo desabou; em 2016, por problemas estruturais houve a interdição do viaduto Santo Amaro também em São Paulo; o ano de 2016 foi marcado pelo colapso da ciclovia do Rio de Janeiro durante os Jogos Olímpicos. Em Fortaleza a ponte do bairro Aerolândia desabou em 2016; também em 2016 a ponte sobre o rio Moju no estado do Pará desabou após uma colisão de uma balsa nos pilares da sua estrutura. $\mathrm{O}$ viaduto da marginal Pinheiros em São Paulo colapsou em 2018; no mesmo ano, o viaduto do Eixo norte de Brasília ruiu; ainda em 2018 a ponte sobre o Rio Madeira no município de Abunã no Acre foi atingida por balsa que faz a travessia dos veículos (GAUCHA, 2014; TVI24, 2016; SOUZA et al., 2018; ECOS, 2018; G1, 2018; OCP, 2018). Além dos casos citados, segundo Vitório (2008), o estado de Pernambuco apresentou falhas estruturais em 18 pontes de sua malha rodoviária.

Os casos apresentados mostram que há fragilidade no tratamento da prevenção de desastres tecnológicos no Brasil e no mundo, em especial na gestão de pontes em alguns estados do país. Isso evidencia que a falta de manutenção somada com a ausência de dispositivos de segurança em pontes corrobora com a possibilidade de colisões, causando assim colapso em suas estruturas.

Diante do grande número de casos de colapsos em estruturas rodoviárias, é notável a necessidade de maior atenção na forma que as estruturas são construídas, visto que, em sua maioria ocorre a ausência dos dispositivos de segurança contra colisões em seus pilares. Essa questão pode ser observada na ponte Newton Navarro em Natal, Rio Grande do Norte, a qual não possui as defensas de segurança dos pilares o que é um risco para o transito de embarcações portuárias durante a noite ou em dias de mar com "ressaca".

\subsection{Vulnerabilidade estrutural da ponte Newton Navarro}

Para conduzir a discussão, é necessário ter clareza no conceito de vulnerabilidade. Para Almeida (2010), esse conceito remete em seu arcabouço para outros termos chaves como resiliência, adaptação, insegurança, ajustamento, exposição e susceptibilidade.

A vulnerabilidade pode ser definida por Cardona (2004) como um seguimento do risco de uma dada comunidade a qual encontra-se exposta a um perigo, assim correspondendo a uma possível recepção de danos, de modo que, a suscetibilidade à eventos perigosos de cunho físico, econômico, político ou social podem causar algum dano a comunidade. Ainda, para UNISDR (2016) a vulnerabilidade abarca condições pré-estabelecidas por elementos ou regimes de cunho físico, social, econômico e ambiental, os quais elevam a suscetibilidade de uma população à perigos ativos.

De acordo com Field et al., (2012), a vulnerabilidade é a possibilidade, propensão ou predisposição que uma dada comunidade pode ser adversamente afetada. A vulnerabilidade está diretamente ligada ao risco, isto é, já que existem distintos tipos de riscos, existem vulnerabilidades diferentes. Aqui destacamos a vulnerabilidade tecnológica a qual Marchezini (2016) aborda, onde, a vulnerabilidade ocorre pelo uso inadequado da técnica na construção de edificações.

No Brasil existe uma política de criação de obras, todavia a manutenção do equipamento já edificado não existe, para Souza et al., (2018) há uma falta de interesse do poder público, onde este somente toma alguma providência quando acontece um desastre. Com toda a tecnologia moderna e perícia empregada nos projetos de executivos de grandes estruturas como a das pontes, estas ainda estão passíveis de colapso como qualquer estrutura já construída em função de fatores como a falha técnica ou falta de manutenção. Estruturas da engenharia civil tendem a apresentar uma grande vida útil, porém, é preciso dar importância ao monitoramento dessas edificações e avaliar se é necessário fazer alguma correção ou aditivo que não estavam previstos no projeto inicial.

Em função disso, tem-se o caso da ponte Newton Navarro a qual não tinha em seu projeto inicial e executivo os dispositivos de segurança nos pilares, contra colisões de navios. Anos após a construção da ponte, o canal do porto de Natal passou a receber navios de maior calado, assim representando um perigo em detrimento da vulnerabilidade estrutural desse equipamento, que a qualquer momento pode receber um impacto direto, provocado por uma colisão de uma embarcação portuária. 
Observa-se na Figura 5 a ausência dos "dolfins" de proteção dos pilares da ponte Newton Navarro. É perceptível a construção de "defensas de plástico e de pneus" contra impacto de embarcações, porém, estas não são estruturas apropriadas, as setas vermelhas mostram os pneus utilizados para amortecer colisões. A Capitania dos Portos considera tais dispositivos insatisfatórios, sendo o ideal a construção de "dolfins" para proteger a estrutura da ponte, assim como foram feitos na ponte Rio-Niterói no Rio de Janeiro, evidenciado na Figura 6.

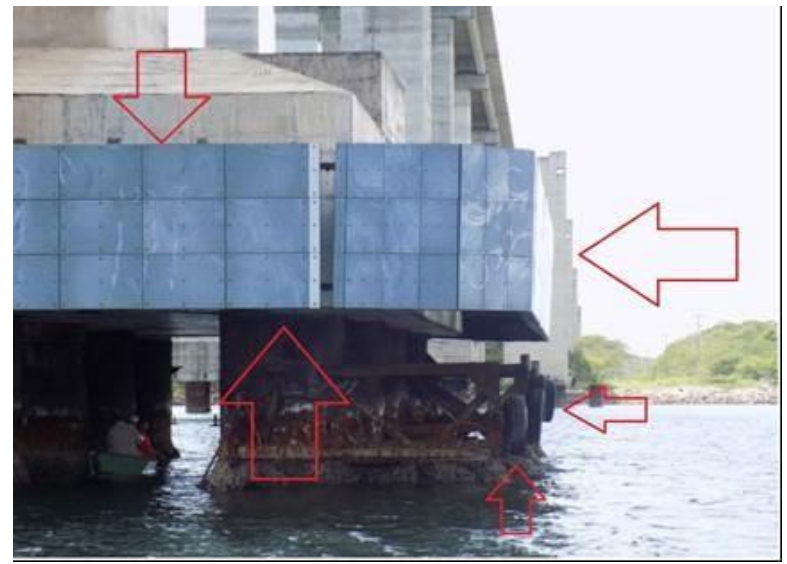

Figura 5 - Pilares da Ponte Newton Navarro. Fonte: acervo dos autores (2017).

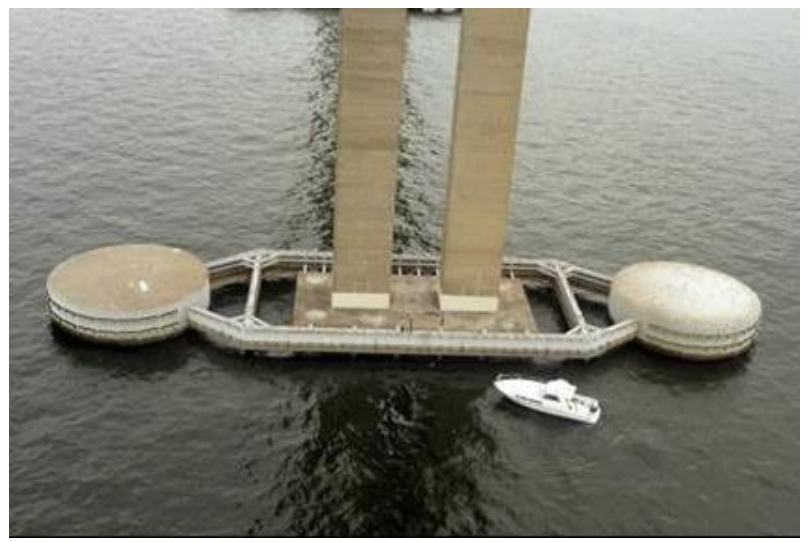

Figura 6 - "Dolfins" na ponte Rio-Niterói. Fonte: Studio Franchetti (2019).

Para Silva (2016) "dolfins" trata-se de uma estrutura circular de grande diâmetro, a qual está construída sobre estacas cravadas no leito do rio, o seu interior pode ser preenchido por areia, brita ou concreto armado (Figura 6). Salienta-se que não há no projeto inicial da construção da ponte Newton Navarro as estruturas dos "dolfins", o que deveria ter sido projetado antes da execução da obra, como mostra os círculos vermelhos na planta final do projeto executivo na Figura 7.

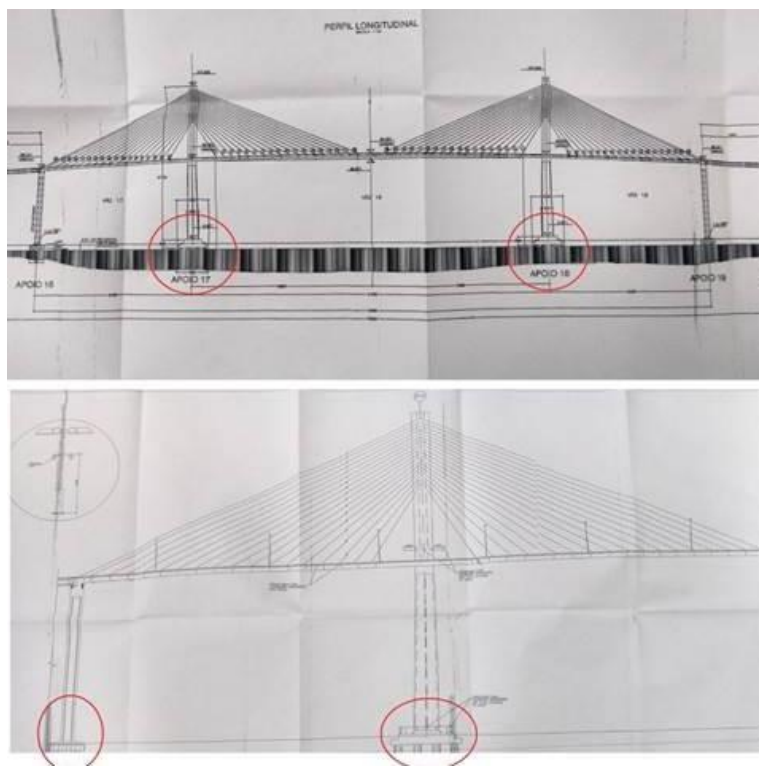

Figura 7 - Planta do projeto de execução da ponte sem os "dolfins". Fonte: modificado pelo autor a partir de SEMURB (2008).

No tocante a ponte Newton Navarro, devido à veiculação de notícias feitas pela Capitania dos Portos de Natal, a $41^{\text {a }}$ Promotoria de Justiça ajuizou a ação civil público contra o estado do Rio Grande do Norte, devido à necessidade urgente de instalação de dispositivos adequados de proteção da ponte, com o objetivo de diminuir os riscos da ponte ruir devido a possíveis colisões de navios (MPRN, 2012).

Após a tramitação na justiça, a Companhia de Docas de Natal realizou em 2015 o estudo do projeto de construção dos "dolfins" da ponte. A construção desse dispositivo de segurança iria ocorrer paralelamente as obras de expansão do porto de Natal e do terminal marítimo de passageiros, cujo valor da obra estava orçada em 90 milhões de reais, sendo uma obra em consórcio do Governo do Estado, Prefeitura do Natal e a Companhia de Docas de Natal (CODERN, 2015).

Pode-se ver na Figura 8 a planta do projeto da construção dos "dolfins" na ponte Newton Navarro, elaborado após anos de operação da estrutura. Nas mesoestruturas, isto é, nos dois pilares centrais da ponte, destacados em vermelho, estão previstos a construção de dez dispositivos, cinco para cada pilar central e para os destacados na cor laranja, os pilares adjacentes com a previsão de construção de quadro dispositivos, sendo dois em cada um desses pilares. 


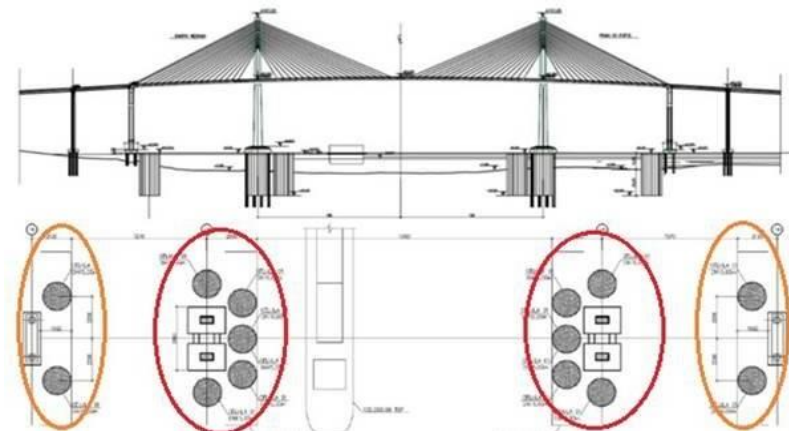

Figura 8 - Planta do projeto de construção dos "dolfins" da ponte Newton Navarro. Fonte: modificado pelo autor a partir de CODERN (2015).

Sobre o trâmite processual do Ministério Público Estadual, o levantamento feito pela promotoria constatou a existência de riscos de acidentes com média e alta complexidade, cujas consequências podem ser de natureza estrutural, patrimonial, ambiental e humana. Diante desses fatos, a promotoria do meio ambiente instaurou o inquérito $\mathrm{n}^{\circ}$ 06.2012.001027-9 que substituiu a ação civil pública (MPRN, 2012).

Posteriormente, após as indagações do MPE, a Secretaria de Infraestrutura do Estado informou que não há recursos para a contratação da empresa para realizar o estudo técnico, bem como dar inicio ao processo licitatório (MPRN, 2012).

Desse modo, a promotoria requisitou ao Conselho Regional de Engenharia e Agronomia - CREA, informações referentes a real situação de riscos dos pilares da ponte em questão. No CREA existem dezessete notificações lavradas pela fiscalização do conselho sobre a ponte Newton Navarro. Os processos protocolados no conselho são contra os empreendedores da construção da ponte, pois os dispositivos de segurança não foram colocados no projeto, como visto na Figura 7 anteriormente (MPRN, 2012).

Tendo em vista essa situação, a Capitania dos Portos de Natal optou por aumentar as restrições de embarcações no estuário enquanto os "dolfins" e os sinalizadores não forem instalados. Além disso, tem-se outro problema no canal do rio Potengi, pois este, não poderá ser dragado enquanto não forem feitos os dispositivos de segurança na ponte, visto o grande fluxo de dragas no estuário. Os recursos para a construção dos "dolfins" seriam pleiteados pelo Programa de Aceleração do Crescimento 2 (MPRN, 2012).

No ano de 2018 o Governo do Estado e a Prefeitura do Natal foram condenados pela promotoria, onde, em caráter de urgência deveria iniciar o processo de construção dos "dolfins" e a instalação dos sinalizadores da ponte Newton Navarro. Na Figura 9 pode-se ver que não há sinalizadores náuticos nos pilares da ponte, além da falta de manutenção na escada de acesso. Nas condenações feitas em juízo, ficou estabelecido que caso não haja o cumprimento das determinações da promotoria, ambas as esferas públicas serão notificadas com a multa de $\mathrm{R} \$ 2$ milhões e R\$ 1 milhão, respectivamente (MPRN, 2018).

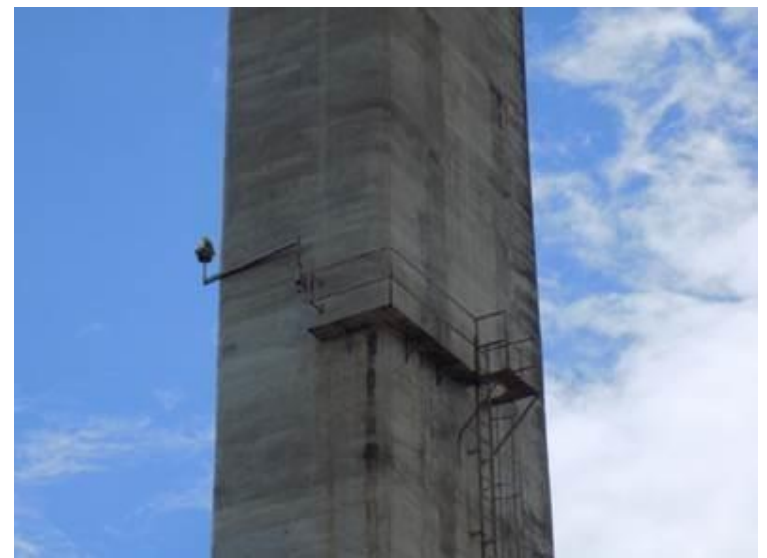

Figura 9 - Falta de manutenção e ausência dos equipamentos de sinalização. Fonte: acervo dos autores (2016).

Com a condenação, ficou estabelecido que o Governo Estadual deverá instalar as defensas (dolfins) da ponte Newton Navarro em até três meses sob a orientação da CODERN e da Capitania dos Portos, com recursos próprios ou por meio de convênio com o Governo Federal. Além disso, o Estado deverá realizar a manutenção dos parafusos que sustentam a vedação na emenda das baias da ponte. O prazo para isso foi de 60 dias e a multa prevista em caso de descumprimento foi de $\mathrm{R} \$ 500 \mathrm{mil}$ (MPRN, 2018).

A Secretaria de Infraestrutura do Estado deve de imediato restaurar os painéis de sinalização náutica diurna e noturna, indicando o melhor ponto de passagem; e uma luz rítmica branca, indicando águas seguras. Essa medida deve ser implementada em 30 dias, com multa de R $\$ 500$ mil caso não seja cumprida (MPRN, 2018).

A promotoria estabeleceu que o município de Natal terá de impedir o tráfego de pedestres, veículos e ciclistas sempre que houver passagem de navios com mais de mil toneladas de deslocamento sob a via. Para cada vez que essa determinação for descumprida, o juiz determinou multa de R $\$ 500$ mil contra a Prefeitura de Natal (MPRN, 2018).

Por fim, a comarca condenou a Prefeitura de Natal a promover uma operação tapa buracos na ponte e a instalar câmeras de monitoramento. Para a correção do asfalto, o prazo foi de 60 dias. Para as câmeras, seis meses. Caso a operação tapa buracos não seja realizada dentro do prazo, a multa prevista é de R\$ 500 mil. Se as câmeras não forem instaladas, a pena prevê pagamento de R $\$ 200$ mil (MPRN, 2018).

Mesmo diante do julgamento da ação civil e em seguida da condenação no ano de 2018, até o presente momento no ano de 2020, a decisão não foi cumprida, assim, essa negligência por parte do Estado e da Prefeitura podem custar caro caso a ponte venha a colapsar, além de onerar o erário público, em caso de desabamento pode colocar a vida de transeuntes em risco.

O magistrado ressaltou que constata-se a partir dos laudos técnicos que a ponte Newton Navarro necessita de obras indispensáveis para a garantia da segurança dos usuários, uma vez que, conforme conclusão técnica dos peritos do MPE, existe o risco iminente de colapso das mesoestruturas de sustentação da ponte, isso em detrimento de uma colisão. Desse modo há risco 
da perda de vidas das pessoas que trafegam na ponte, bem como risco ambiental no rio e no ecossistema de manguezal nas adjacências da ponte, na hipótese de derramamento de materiais nocivos que são transportados pelos navios que trafegam no canal, assim requerendo elevados custos financeiros de respostas para esse desastre, os quais podem ser maiores do que o investimento na construção dos dispositivos de segurança (MPRN, 2018).

Diante dos fatos expostos pelos especialistas, o juiz deferiu a sentença e ressaltou que meio ao princípio da reserva do possível, o Estado deve cumprir a determinação se tiver recursos para tal reforma, mesmo assim o Estado não pode negligenciar tamanho risco, visto que a ausência dos dispositivos de segurança coloca em risco a vida das pessoas que trafegam diariamente pela ponte. Assim se faz importante a execução do projeto de construção dos "dolfins" no sentido de mitigar os riscos associados a estrutura.

Conforme mencionado acima, foi possível constatar que há a existência de riscos tecnológicos de forma crônica na ponte Newton Navarro, visto que desde a idealização do projeto não foram acrescidas as estruturas dos dispositivos de segurança, como sinalizadores e as defensas (dolfins) de proteção dos pilares. Assim, todas as vezes que um navio entra ou saí do porto de Natal, há o risco iminente de colisão nos pilares. Desde a inauguração da ponte a estrutura está vulnerável a ruir em função do risco de colisão nos pilares.

Cabe aqui ainda destacar que outra pesquisa realizada na temática por Souza et al. (2018) sobre os riscos na Ponte de Igapó, no estuário do Rio Potengi (o mesmo estuário que está localizada a ponte Newton Navarro), foi objeto de pauta jornalística em todos os telejornais, rádios, blogs e mídias sociais da cidade (TVU, 2017; GEORISCO, 2017; UFRN, 2017; 2018). O qual gerou muita mobilização da mídia e de parlamentares da cidade, assim, foi protocolado no Ministério Público uma Ação Civil Pública cobrando a reforma da ponte de Igapó, como mostra a Figura 10. Após essa ação, os trâmites licitatórios para a reforma da ponte de Igapó foram realizados e a reforma foi finalizada, conforme mostra a Figura 11.

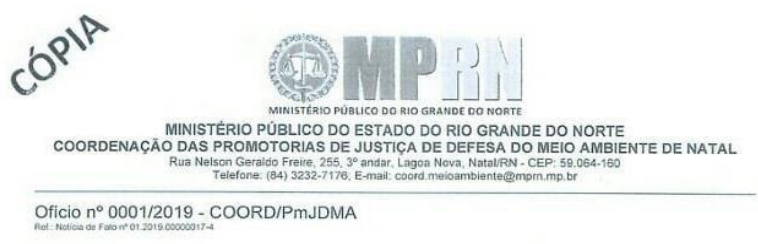

Natal/RN, 10 de janeiro de 2019.

A Sua Excelência a Senhora

Clarisier Azevedo Cavalcante de Morais

Procuradora da República no Estado do Rio Grande do Norte

Avenida Deodoro da Fonseca, 743, Tirol, Natal/RN, CEP: $59020-600$

$3222-3952 / 3914$

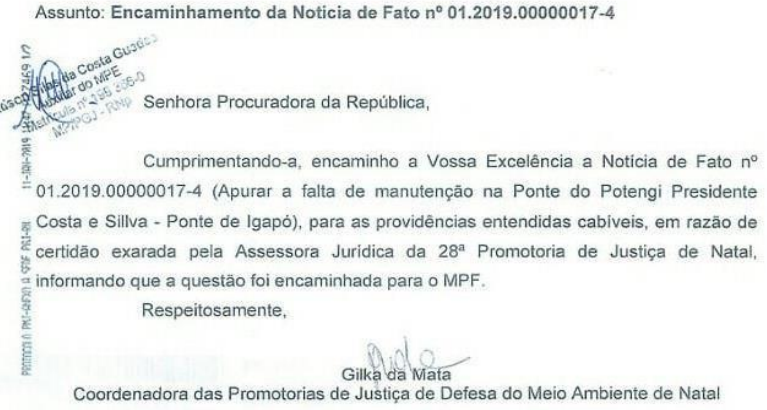

Figura 10 - Ação civil pública da Ponte de Igapó. Fonte: MPRN (2019).

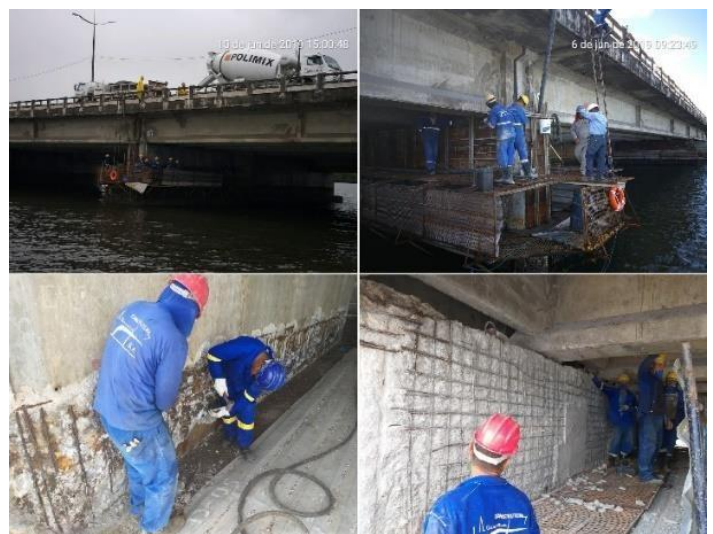

Figura 11 - Canteiro de obras da reforma da Ponte de Igapó. Fonte: acervo dos autores (2019). 


\section{CONSIDERAÇÕES FINAIS}

Considerando os fatos descritos neste trabalho, ressalta-se que há vulnerabilidade estrutural na ponte Newton Navarro de forma continua, desde quando a ponte foi inaugurada. A Capitania dos Portos de Natal, realizou algumas restrições de navegação no canal de acesso ao porto de Natal. Essas restrições ocorreram afim de evitar que navios passem sob a ponte pela noite, para assim, evitar colisões nos pilares devido a falta de visibilidade.

Embora o Ministério Público Estadual do Rio Grande do Norte tenha emitido a condenação jurídica ao município de Natal e ao Governo do Estado por não terem construído as defensas (dolfins) e por não terem instalado os sinalizadores, até o presente momento, as duas esferas do executivo não tomaram nenhuma medida a fim de mitigar os riscos na ponte, com isso, amplia-se a vulnerabilidade estrutural da ponte Newton Navarro.

Como o porto de Natal possui um grande fluxo de navios, sendo de importação e exportação de mercadorias do Estado, a Companhia de Docas do Rio Grande do Norte realizou o projeto dos "dolfins" dos pilares da ponte Newton Navarro. Porém, a obra que estava prevista no pacote da copa do mundo de 2014, por falta de recursos ainda não foi iniciada, por mais que a justiça tenha instituido o Estado a realizar as adequações no ano de 2018, até agora em 2020 nada foi feito.

Dada às colocações, o presente estudo destacou a preocupação com os riscos na ponte Newton Navarro. A partir desta pesquisa, considera-se que novas ações jurídicas possam ser geradas, no sentido de cobrar melhorias na estrutura da ponte.

Além disso, há necessidade da implementação de um setor de gestão de pontes do Estado, dentro da Secretaria de Infraestrutura Estadual, com cooperação do Departamento Nacional de Infraestrutura de Transportes. Esse setor deverá realizar inspeções, avaliações e correções necessárias nas pontes potiguares. Para isso, é necessário o gerenciamento do setor para realização da averiguação de dados sobre o estado da estrutura; realização de estudos geotécnicos e de tráfego; ou ainda a intervenção qualificada de engenharia. É importante frisar que ocorrendo a implementação desse setor, as estruturas de pontes como a Newton Navarro deveriam receber os aditivos na obra. Isso oneraria o erário público de forma inferior, do que uma intervenção maior em caso de acidentes.

Portanto, o setor de gestão de pontes proposto é uma forma de gerir melhor a estrutura das pontes no estado potiguar, a fim de evitar possíveis novos desastres, principalmente na ponte Newton Navarro, a qual vindo a ruir, causaria danos ambientais, econômicos e humanos de grandes proporções no estuário do rio Potengi.

\section{REFERÊNCIAS}

ALMEIDA, L. Q. Vulnerabilidades Socioambientais em Rios Urbanos: Bacia Hidrográfica do Rio Maranguapinho, Região Metropolitana de Fortaleza, Ceará. Tese de doutorado apresentado ao Departamento do Instituto de Geociências e Ciências Exatas, Universidade Estadual Paulista, Rio Claro. 2010. 278 p.
CARDONA, O. D. et al. The need for rethinking the concepts of vulnerability and risk from a holistic perspective: a necessary review and criticism for effective risk management. Mapping vulnerability: Disasters, development and people, v. 17, p. 37-51, 2004.

CASTRO, M.; PEIXOTO, M. N. O.; RIO, G. A. P. Riscos ambientais e geografia: conceituações, abordagens $e$ escalas. Anuário do Instituto de Geociências, Rio de Janeiro: UFRJ, v.28, n.2, p.11-30. 2005.

COMPANHIA DE DOCAS DO RIO GRANDE DO NORTE. (2019). Porto de Natal é destaque na exportação de frutas. Disponível em: http://codern.com.br/porto-de-natal/. Acesso em 25/02/2019.

COMPANHIA DE DOCAS DO RIO GRANDE DO NORTE. (2015). Projeto de ampliação do porto de Natal. Natal, RN.

CONSOLAZIO, G. R. et al. Development of improved bridge design provisions for barge impact loading. Gainesville, Florida: Department of civil and coastal engineering University of Florida, 2008.

Ecos da Notícia. (2018). Acidente: balsa atinge obras da ponte sobre o rio Madeira na manhã desta segunda. Disponível em:_https://ecosdanoticia.net.br/2018/04/16/acidente-balsaatinge-obras-da-ponte-sobre-o-rio-madeira-na-manhadesta-segunda.html. Acesso em 25/02/2019.

FERREIRA, A. N. Estudo do efeito de acidentes na hidrovia Tietê- Paraná: Aspectos Preventivos. Dissertação de mestrado apresentada a Escola Politécnica da Universidade de São Paulo. Departamento de Engenharia Naval e Oceânica. São Paulo: 2000, 168p.

FIELD, C. B. et al. IPCC, 2012: Managing the risks of extreme events and disasters to advance climate change adaptation. $A$ special report of Working Groups I and II of the Intergovernmental Panel on Climate Change. Cambridge University Press, Cambridge, UK, and New York, NY, USA, v. 30, n. 11, p. 7575-7613, 2012.

G1. Portal de Notícias da Globo. (2016). Balsa bate em dois pilares da ponte da alca viária sobre o rio Muju. Disponível em: http://g1.globo.com/pa/para/noticia/2016/10/balsa-bateem-dois-pilares-da-ponte-da-alca-viaria-sobre-o-riomoju.html. Acesso em 25/02/2019.

G1. Portal de Notícias da Globo. (2018). São Paulo já teve ponte caindo e viadutos interditados por incêndios. Disponível em: https://g1.globo.com/sp/saopaulo/noticia/2018/11/15/sp-ja-teve-ponte-caindo-em-rio-eviadutos-interditados-por-incendio-relembre.ghtml. Acesso em 25/02/2019.

G1. Portal de Notícias da Globo. (2018). Tufão Jebi fecha aeroporto e petroleiro colidi com ponte no Japão. Disponível em: https://g1.globo.com/mundo/noticia/2018/09/04/tufaojebi-fecha-aeroporto-e-faz-petroleiro-colidir-com-ponte-nojapao.ghtml. Acesso em 25/02/2019. 
GEORISCO. Georisco na Mídia: Entrevista sobre pesquisa dos riscos da Ponte de Igapó. Disponível em: https://grupodepesquisageorisco.blogspot.com/2017/02/geo risco-na-midia-entrevista-sobre.html. Acesso em: $15 / 02 / 2017$

JORNAL EM INTERNACIONAL. (2018). Viaduto desaba $e$ deixa 22 mortos na cidade italiana de Gênova. Disponível em:

https://www.em.com.br/app/noticia/internacional/2018/08/ 14/interna_internacional,980139/viaduto-desaba-e-deixa22-mortos-na-cidade-italiana-de-genova.shtml. Acesso em 25/02/2019.

JORNAL OCP NEWS. (2018). Viaduto desaba e deixa vão de quase dois metros em São Paulo. Disponível em: https://ocp.news/seguranca/viaduto-desaba-e-deixa-vao-dequase-dois-metros-em-sao-paulo. Acesso em 25/02/2019.

JORNAL TRIBUNA DO NORTE. (2012). Ponte: MP quer proteção em pilares. Disponível em: http://www.tribunadonorte.com.br/noticia/ponte-mp-querprotecao-em-pilares/225990. Acesso em 25/02/2019.

JORNAL TRIBUNA DO NORTE. (2013). Juiz determina realização de melhorias na ponte Newton Navarro. Disponível em: http://www.tribunadonorte.com.br/noticia/juiz-determinarealizacao-de-reparos-e-melhorias-na-ponte-newtonnavarro/241522. Acesso em 25/02/2019.

JORNAL TRIBUNA DO NORTE. (2018). Solução passam por transporte público. Disponível em: http://www.tribunadonorte.com.br/noticia/solua-a-espassam-por-transporte-paoblico/401702. Acesso em 25/02/2019.

LIEBER, R. R.; ROMANO-LIEBER, N. S. Risco e precaução no desastre tecnológico. Cadernos de Saúde Coletiva, v. 13, n. $1,2005$.

MAZARIM, D. M. Histórico de pontes estaiadas e sua aplicação no Brasil. Dissertação de mestrado apresentada a Escola Politécnica da Universidade de São Paulo/Departamento de Engenharia de Estruturas e Geotécnica. 2011. 125 p.

MINISTÉRIO PÚBLICO DO ESTADO DO RIO GRANDE DO NORTE. (2018). Em ação do MPRN, Justiça condena Estado e Município de Natal a realizarem melhorias na Ponte Newton Navarro. Disponível em: http://www.mprn.mp.br/portal/inicio/noticias/9303-emacao-do-mprn-justica-condena-estado-e-municipio-denatal-a-realizarem-melhorias-na-ponte-newton-navarro. Acesso em 25/02/2019.

MINISTÉRIO PÚBLICO DO ESTADO DO RIO GRANDE DO NORTE. (2012). Ação Civil Pública no 06.2012.001027-9. $41^{\text {a }}$ Promotoria da Comarca de Natal. Natal, RN.

Portal de Notícias TVI24. (2019). Navio cruzeiro colide com ponte provocando dois mortos. Disponível em: https://tvi24.iol.pt/internacional/colisao/navio-de-cruzeirocolide-com-ponte-provocando-dois-mortos. Acesso em 25/02/2019.

Portal Gauchazh. 2014. Barco contra ponte do rio Tres Forquilhas na BR 101. Disponível em: https://gauchazh.clicrbs.com.br/transito/noticia/2014/01/bar co-colide-contra-ponte-do-rio-tres-forquilhas-na-br-101cj5vh8w8t0b95xbj0xfyqri6v.html. Acesso em 25/02/2019

QUARANTELLI, E. L. What is a disasters? Perspectives on the question. Abingdon: Routledge, 1998.

PREFEITURA MUNICIPAL DE NATAL. Secretaria Municipal de Meio Ambiente e Urbanismo: Estudo de Impacto Ambiental/Relatório de Impacto Meio Ambiente da ponte Newton Navarro. Natal, RN. 2008.

SILVA, N. P. da. Sistemas de proteção de pilares de pontes contra colisão de embarcações: Análise e verificação de dois sistemas. Trabalho de Conclusão de Curso em Engenharia Civil e ambiental. Universidade de Brasília, Brasília/DF, 2016. 105 p.

SOUZA, L. de S. et al. A Percepção da população da face ao risco de desastre tecnológico na Ponte de Igapó, Natal - RN, Brasil. Territorium, Estudos Cindínicos. v. 2, p. 153. Coimbra/ PT: 2018.

TVU - UFRN. Estudo aponta que ponte de igapó está com a estrutura danificada. Disponível em: https://www.youtube.com/watch?v=BevamAdoPjM\&featur e=youtu.be. Acesso em: 25/05/2017.

UFRN - UNIVERSIDADE FEDERAL DO RIO GRANDE DO NORTE. ESTUDANTE DA UFRN PESQUISA RISCOS DA PONTE DO BAIRRO DE IGAPÓ. Disponível em: https://www.ct.ufrn.br/estudante-da-ufrn-pesquisa-riscosda-ponte-do-bairro-de-igapo/. Acesso em: 13/03/2017.

UFRN - UNIVERSIDADE FEDERAL DO RIO GRANDE DO NORTE. Segundo estudo da UFRN, 79\% dos potiguares não se sentem seguros ao transitar na Ponte de Igapó. Disponível em: https://ufrn.br/imprensa/materiasespeciais/13797/pesquisa-da-ufrn-aponta-que-79-dospotiguares-nao-se-sentem-seguros-ao-transitar-na-ponte-deigapo. Acesso em: 03/03/2018.

UNIÃO INTERNATIONAL STRATEGY FOR DISASTER REDUCTION. Como construir cidades mais resilientes: um guia para gestores públicos locais. Genebra: UNISDR, 2009. Disponível em: http: //www.unisdr.org/we/inform/terminology. Acesso em: 20/02/2019.

UNISDR. Report of the open-ended intergovernmental expert working group on indicators and terminology relating to disaster risk reductionUnited Nations General Assembly. $2016 . \quad$ Genebra. Disponível em: https://www.preventionweb.net/files/50683_oiewgreporten glish.pdf. Acesso em: 25/02/2020. 
VEYRET, Y.; RICHEMOND, N. M. Definições e vulnerabilidades do risco. Os riscos: o homem como agressor e vítima do meio ambiente. São Paulo: Contexto, p. 25-46, 2007.
VITORIO, J. A. P. Avaliação do grau de risco estrutural de pontes rodoviárias de concreto. In: $50^{\circ}$ Congresso Brasileiro do Concreto, Salvador, 2008. Anais... Salvador, 2008.

Recebido em: 22/07/2019

Aceito para publicação em: 28/05/2020 